\title{
Retraction Note to: Oolong Tea Drinking Could Help Prevent Bone Loss in Postmenopausal Han Chinese Women
}

\author{
Guibin Wang ${ }^{1} \cdot$ Liu Hongmei Liu ${ }^{2}$ Zhenchun Zhang ${ }^{3} \cdot$ Fengfang $\mathrm{Zhang}^{4} \cdot \mathrm{Shufa}^{3}{ }^{3} \cdot$ \\ Yang Chen $^{5} \cdot$ Huanli Zhao ${ }^{1}$
}

Published online: 20 May 2017

(C) Springer Science+Business Media New York 2017

\section{Retraction Note to: Cell Biochem Biophys (2014) 70:1289-1293 \\ DOI 10.1007/s12013-014-0053-y}

Upon the request of the authors, the Editor-in-Chief retracts this paper and its erratum, as the authors have confirmed that they had included material for which they had not obtained the required rights and permissions.

Guibin Wang, Hongmei Liu, Zhenchun Zhang, Fengfang Zhang, Shufa Li, Yang Chen, Huanli Zhao (2014). Oolong tea drinking could help prevent bone loss in postmenopausal Han Chinese women. Cell Biochemistry and Biophysics 70(2): 1289-1293. Doi: 10.1007/s12013-0140053-y.

Wang, G., Liu, H., Zhao, H. et al. (2014). Erratum to: Oolong tea drinking could help prevent bone loss in postmenopausal Han Chinese women. Cell Biochemistry and Biophysics 70: 1295. Doi:10.1007/s12013-014-0171-6.

The online version of the original article can be found at doi:10.1007/ s12013-014-0053-y.

Huanli Zhao

drhuanlizhao@163.com

1 Radiology Department X-Ray Room, Linyi People's Hospital, Shandong, China

2 Department of Surgery, Linyi People's Hospital, Shandong, China

3 Department of Orthopedics, Linyi People's Hospital, Shandong, China

4 Department of Endocrinology, Linyi People's Hospital, Shandong, China

5 Department of Rheumatology, Linyi People's Hospital, Shandong, China 